\title{
Garantías Ambientales en la Constitución: Un nuevo modelo ecológico-político para Costa Rica y el resto del mundo
}

\author{
Gabriel Quesada A. \\ Centro de Educación Ambiental, Universidad Estatal a Distancia, Mercedes de Montes de Oca, San José, Costa Rica; \\ gquesada@uned.ac.cr
}

Recibido 27-IX-2008. C Corregido 22-II-2009. Aceptado 25-III-2009.

\begin{abstract}
Environmental Guarantees in the Constitution: a new ecological-political model for Costa Rica and the rest of the world. In the last thirty years significant changes to protect the environment have been introduced in the judicial, administrative and social systems. Costa Rica is a well known international model in the field of sustainable development, and here I present a proposal for adding environmental gaurantees to the Costa Rican Constitution. One of the most important changes in the Costa Rican judicial system has been the introduction of an environmental amendment in the Constitution (Article 50). However, it is still fundamental to introduce a Title of Environmental Guarantees in the Constitution of Costa Rica, with these components: first, the State, the public and the private sector have the duty of defending the right to a safe environment; second, public domain over environmental issues, and third, the use of the environment should be regulated by scientific and technical knowledge. If current efforts succeed, Costa Rica will be the first country in the world to include Environmental Guarantees in its Constitution. This would be an example to other nations. Rev. Biol. Trop. 57 (3): 461-472. Epub 2009 September 30.
\end{abstract}

Key words: environment, environmental sustainability, public domain, environmental guarantees.

\section{Ecologismo, ciencia y garantías ambientales}

El ecologismo es el producto de la evolución científica que ha experimentado la humanidad durante las tres últimas décadas del siglo XX a través de la ecología; ciencia que integra los factores abióticos y bióticos, incluyendo a los seres humanos y el ecólogo, especialista, libre pensador que integra las diferentes variables que componen el ambiente (Mata \& Quevedo 2005). El ecologismo, es además, un movimiento científico-político que se deriva de la conciencia que ha adquirido la humanidad sobre los impactos que este ha provocado sobre el ambiente.

Es a través de la epistemología -teoría de la ciencia- que se podría ordenar el conocimiento y establecer los vínculos que existen entre la filosofía, la ciencia y el ecologismo. Es la forma práctica en que se utiliza el conocimiento para dar respuesta a los cambios que sufren los ecosistemas, producto de actividades humanas.

Si el ecologismo no cuenta con el conocimiento científico, no tendría las bases para proteger el ambiente y si la ciencia no tiene una filosofía ecologista que la respalde, no respondería a las necesidades humanas.

En otras palabras, el ecologismo sin ciencia es inoperante y la ciencia sin ecologismo es peligrosa.

Por su parte, el ecologismo rompe con los conceptos de determinismo y reduccionismo biológico y cultural al establecer que lo dialéctico prevalece ante lo causístico, lo relativo a lo absoluto, lo indeterminado a lo determinado y lo sistémico a lo reducido. El ecologismo antepone el conocimiento, ante el prejuicio y el dogma (Quesada 1980). 
Para el ecologismo es fundamental el papel que juega el clima, el ciclo hidrogeológico, el suelo y el ciclo de los nutrientes, las relaciones simbióticas, la importancia del metabolismo y la fotosíntesis en el ecosistema y la sostenibilidad ambiental. A contrario censo, para la economía clásica, neoclásica, así como el socialismo clásico ninguno de estos factores es determinante. Para la economía clásica lo importante son los ingresos producto de los recursos naturales, la fuerza laboral y el capital invertido. Para la economía neoclásica, no solo se desechan los recursos naturales como uno de los principales activos, sino que toma en cuenta, únicamente, la fuerza laboral y el capital invertido (Repetto 1992). Para la economía socialista clásica, la naturaleza estaba relacionada con el valor de uso y centró su sistema teórico en el valor de cambio. Nunca consideró la protección del ambiente (Quesada 2008).

Por eso es fundamental transformar los paradigmas de la economía de mercado y de la economía socialista clásica, a una ecologíaeconómica donde los factores ambientales sean los principales actores. El homo ecológico debe prevalecer sobre el homo económico. El ser humano es parte del ambiente y no debe responder a los intereses económicos, únicamente.

La destrucción de ecosistemas, la desaparición de especies, la contaminación de las aguas, el aire, entre otros, han provocado una severa devastación ambiental. El planeta no tiene la capacidad de soporte para continuar este proceso destructivo (Brown 2001).

Las Garantías Ambientales servirán para establecer ese nuevo paradigma ecológico, económico, político y social, ya que su concepción y doctrina están basados en los principios epistemológicos que sustentan al ecologismo. Es la permanente interacción que existe entre factores abióticos, bióticos y humanos y los cambios energéticos que experimentan estos factores.

\section{Energía de sistemas}

La energía de sistemas es la base fundamental para el análisis de los fenómenos ambientales. Es el principio básico para la comprensión de los sistemas y su constante transformación energética. La energía es la capacidad latente o manifiesta para ejercer una fuerza a lo largo de un camino, es la capacidad de realizar trabajo.

La energía se manifiesta en distintas formas y se le considera proporcional a la masa de un cuerpo. Por lo tanto, la energía relacionada al movimiento se llama cinética, la energía de posición se llama potencial y la energía relacionada a la composición de la materia se denomina interna (Odum 1983).

La ciencia que estudia las leyes de la energía se conoce como termodinámica y se compone de las siguientes leyes:

1. La primera ley o ley de la conservación de la energía establece que la cantidad total de energía en todas sus formas es constante. La energía no se crea ni se destruye, solo se transforma.

2. La segunda ley o ley de la entropía establece que en el universo existe una tendencia a la degradación de la energía. Es el grado de desorden que poseen las moléculas que integran un cuerpo o el grado de irreversibilidad alcanzada después de un proceso que implique transformación de energía. En el ecosistema, la energía es transferida en forma de alimento de un organismo a otro y se disipa en forma de calor, el cual no es transferible. El resto es almacenado como tejido vivo.

En la naturaleza, la segunda ley también se interpreta de la siguiente manera: la energía fluye desde un nivel de alta intensidad a un nivel de débil intensidad con el fin de efectuar un trabajo útil en la cadena de procesos ambientales. Como la energía se degrada continuamente a formas cada vez menos utilizable, la biomasa vegetal será indudablemente mucho mayor que la animal. De ahí la importancia que juegan los bosques en el ecosistema.

3. La tercera ley establece que la entropía es igual a cero cuando la temperatura alcanza 
el cero absoluto $\left(-273{ }^{\circ} \mathrm{C}\right)$. En otras palabras, a $0{ }^{\circ} \mathrm{K}$ (Kelvin) la entropía es igual a cero.

4. La cuarta ley o principio del máximo poder establece que un sistema prevalece cuando desarrolla estructuras que maximicen el flujo de energía útil. Bajo este enunciado Lotka (1922) la propuso como la cuarta ley de la termodinámica, ya que es base importante para la comprensión de los flujos de energía en el ecosistema. El principio del máximo poder hace hincapié en la necesidad de optimizar la conversión, transmisión y consumo de energía.

La comprensión de las leyes termodinámicas es fundamental, no solo para conocer los fenómenos naturales y sus transformaciones energéticas, sino para establecer los principios filosóficos y científicos de planificación y organización ambiental. La teoría de los sistemas es una de las ciencias que más ha contribuido a comprender las leyes de la energía y que establece sus principios en los procesos de transformación de la energía.

\section{Teoría de sistemas}

El concepto de sistema es tan viejo como la filosofía occidental. Fueron los griegos, primeros filósofos y científicos, que consideraron, en el mundo empírico, un orden o cosmos inteligible. Una primera formulación de ese orden cósmico fue la visión aristotélica con su noción de, el todo es más que la suma de sus partes, como definición del fenómeno de los sistemas (von Bertalanffy 1987).

Otro número considerable de precursores contribuyeron a sentar las bases de la teoría de sistemas. Nicolás de Cusa, en el siglo XV, propuso la coincidencia oppositorum, que es la lucha de las partes dentro de una totalidad. Godofredo Leibniz, la jerarquía de las mónadas que se parece a la de los modernos sistemas. Federico Hegel y Carlos Marx a través de la estructura dialéctica del pensamiento. Gustavo Fechner y sus comunidades de vida, como uno de los precursores de lo que hoy se conoce como los ecosistemas.
Alfredo Lotka y sus ecuaciones diferenciales simultáneas, como base para la teoría de sistemas dinámicos y las ecuaciones de Vito Volterra, utilizadas para el estudio de la competencia de las especies.

Carlos von Bertalanffy enuncia en 1930, la teoría general de los sistemas como el primer intento de unidad de la ciencia a diferencia de la ciencia clásica donde los hechos observados estaban relacionados a cadenas causales aisladas, es decir, relaciones entre dos o pocas variables (von Bertalanffy 1987). Para von Bertalanffy, los elementos en la naturaleza están interrelacionados, lo que conduce a un resultado o producto que se define como sistema. Un sistema es un grupo de partes o de eventos que interactúan entre sí. Otro aspecto importante en el concepto de sistema, es que cada elemento por pequeño que sea, tiene un nivel de influencia sobre los otros. Situación que crea una interdependencia entre las partes. Otra característica del sistema es el trabajo coordinado y relacionado que existe en su interior. A este fenómeno se le conoce como sinergia.

La versión simplificada de un sistema es lo que se conoce como modelo y se utiliza para analizar e interpretar lo que es un sistema. Existen dos tipos básicos de sistemas: abiertos y cerrados. Un sistema abierto es aquel que tiene intercambio con su ambiente o el que tiene una o más entradas y salidas. La biosfera es un ejemplo de sistema abierto, con energía solar y materia cósmica de entrada y radiación infrarroja, combinada con moléculas, de salida. Un sistema cerrado es aquel que carece de intercambio con su medio y está totalmente aislado. Un ejemplo de sistema cerrado es una botella de agua sellada con agua; en la cual se produce evaporación y condensación simultáneamente.

Ahora bien, la teoría cuántica y la teoría de la relatividad transforman los conceptos de la física clásica a una visión integradora o sistémica. El todo es más que la suma de las partes; son las redes que existen en el universo $\mathrm{y}$ en el ambiente. 


\section{Ecología de sistemas}

La ecología de sistemas está íntimamente ligada a la teoría de sistemas. Su interpretación parte del principio de que todos los sistemas en la naturaleza están interrelacionados. Existen células y órganos que forman los sistemas biológicos, organismos y componentes físicos que forman sistemas ecológicos y la interacción de los seres vivos y los ecosistemas que forman el ambiente (Odum 1983).

El término ecología fue propuesto por el biólogo alemán, Ernesto Haeckel en 1866, lo llamó Oecologie y definió su ámbito de aplicación como el estudio de la relaciones entre los animales y su ambiente. Por tanto, el ambiente es la unidad de estudio fundamental de la ecología; está compuesto de elementos abióticos y bióticos y su funcionamiento se deriva de las interacciones entre todos sus elementos (Smith \& Smith 2000). Los elementos abióticos están constituidos por materia inorgánica, rocas, suelo, agua y materia orgánica, carbohidratos y proteínas, producto de la actividad de los seres vivos. Los elementos bióticos están constituidos por seres vivos que se dividen en autótrofos (productores), heterótrofos (consumidores), saprótrofos (descomponedores).

Los autótrofos son organismos que transforman la energía lumínica en energía química, utilizando sustancias inorgánicas, a través del proceso de fotosíntesis. Los heterótrofos son organismos que consumen otros organismos y se dividen en herbívoros o consumidores primarios, se alimentan principalmente de plantas, los carnívoros o consumidores secundarios se alimentan generalmente de los herbívoros. Los saprótrofos son organismos que obtienen su alimento de moléculas ricas en energía que encuentran en los tejidos de los organismos muertos (Smith \& Smith 2000). Es a través de un metabolismo incesante y el flujo de energía que la vida se produce continuamente, se repara y se perpetúa (Margulis 1998)

La transferencia de energía, de un organismo a otro, en una serie de niveles tróficos se denomina cadena alimenticia. Entre cada nivel trófico se ha demostrado que la energía se degrada de un organismo a otro aumentando la entropía de la siguiente manera: un autótrofo elabora 1000 calorías (c), el herbívoro aprovecha $100 \mathrm{c}$ en forma de tejido herbívoro, el carnívoro aprovecha $10 \mathrm{c}$ de energía en forma de tejido carnívoro y finalmente el último carnívoro aprovecha 1c de energía en forma de carnívoro final.

Las Garantías Ambientales tienen su base científica en la energía de los sistemas, en la teoría de los sistemas y en la ecología de los sistemas, en síntesis, en las interrelaciones inorgánicas y orgánicas que se establecen entre los organismos, incluyendo al ser humano.

\section{Antecedentes históricos de las Garantías Ambientales en Costa Rica}

Costa Rica es un país de gran riqueza ecológica y humana por su localización y características físicas. Al ubicarse entre dos masas continentales, el hemisferio norte y el hemisferio sur, el país cuenta con una rica biodiversidad de especies continentales y marinas, residentes y migratorias, así como gran cantidad de especies endémicas. Situación que se consolidó hace tres millones de años al unirse el hemisferio norte con el hemisferio sur, a través de istmo centroamericano. A nivel humano, la situación no fue diferente. Costa Rica ha sido la frontera sur de Mesoamérica, como la frontera norte de Suramérica. Diferentes grupos aborígenes habitaron nuestras tierras, enriqueciendo su diversidad cultural y étnica.

Científicamente se ha demostrado que el país cuenta con más de $5 \%$ de las especies del planeta, en un territorio continental de $51100 \mathrm{~km}^{2}, 0.1 \%$ de la superficie de la tierra y un territorio marino de $589000 \mathrm{~km}^{2}$. Por tanto, el territorio costarricense tiene una extensión de $640100 \mathrm{~km}^{2}$.

En un área tan pequeña existen aproximadamente 12000 especies de plantas. El número de animales no deja de ser menos importante, existen unas 300000 especies de insectos, 848 especies de aves, 237 especies de mamíferos, 218 especies de reptiles, 143 especies de anfibios, 130 especies de peces continentales 
y unas 800 especies de peces marinos en el Pacífico y unas 500 especies de peces marinos en el Caribe (Obando 2002)

Esta riqueza ecológica y cultural siempre formó parte del desarrollo político, económico y social de los grupos aborígenes. Su filosofía y visión del cosmos y del mundo estaban sustentadas en los fenómenos naturales y sus interrelaciones.

Es a partir de la llegada del conquistador español que se inicia una transformación cualitativa y cuantitativa de los patrones ambientales y culturales del país. Primero, por el interés de la monarquía española de consolidar su poder económico y político a nivel internacional y segundo, para explotar los recursos naturales y humanos que contribuirían a consolidar su imperio. Durante la colonia, la situación no fue diferente ya que se mantuvieron los patrones de administración y explotación de recursos similares a los de la conquista.

Es con la introducción del café, que el país se consolida como República y se inicia una nueva etapa en la historia nacional. Se transforma el ecosistema a un agroecosistema, donde se combinan especies de árboles de la flora costarricense con las plantas de café. La cobertura vegetal estaba compuesta principalmente de leguminosas que no solo daban sombra al cafeto, sino que introducían nitrato al suelo, producto de la transformación bacteriana. El mantillo en el suelo, también era parte importante en la formación de nutrientes en los antiguos cafetales. Sin embargo, a partir de la década del 50, los agroecosistemas tradicionales del café se cambian por plantaciones con poca cubierta vegetal o por plantaciones expuestas al sol. Este cambio, trae como consecuencia la introducción de agroquímicos, como fertilizantes y pesticidas que provocan un impacto negativo al ambiente por su uso indiscriminado. Otro serio contaminante es el lanzamiento de broza y mieles a ríos y riachuelos del Valle Central, producto del procesamiento del café.

La actividad bananera fue otro factor que transformó el ecosistema costarricense. Durante la construcción del ferrocarril a la zona Caribeña se otorgaron miles de hectáreas de bosque tropical húmedo a compañías extranjeras para la explotación del banano. Años más tarde la expansión se incrementó a la zona del Pacífico Central y Sur. En la actualidad muchas de las viejas zonas bananeras fueron abandonadas por agotamiento y acumulación de cobre en los suelo. El uso de agroquímicos sin el control y las regulaciones adecuadas, produjo la esterilización masiva de seis mil trabajadores bananeros en la zona de Río Frío, provincia de Heredia. Este caso se discutió en una Corte Federal en el estado de Texas, Estados Unidos. Los trabajadores y sus abogados cobran sumas cuantiosas a las compañías bananeras, como indemnización por los daños producidos en su sistema reproductivo.

Como consecuencia un grupo de costarricenses preocupados por los ecosistemas nacionales, presentó un juicio sin precedentes ante el Tribunal Internacional del Agua en el año de 1992. Dicho tribunal fue auspiciado por el gobierno de Holanda, con el respaldo de la Unión Europea y la Comunidad Científica Internacional. Los resultados del juicio fueron de gran trascendencia, toda vez que se establece la primera jurisprudencia internacional en contra de las compañías bananeras que producen severos impactos ambientales en el trópico costarricense (Quesada 1992).

Durante la década de los años 50, se introduce otra actividad no menos perjudicial que el banano, la ganadería extensiva. La ganadería extensiva fue la responsable de la destrucción de más de $60 \%$ de bosque primario y secundario a nivel nacional, provocando una tasa de deforestación de 60000 ha por año. Es la ganadería extensiva la responsable de la erosión de millones de toneladas de suelo productivo y de la desaparición del hábitat de gran cantidad de especies de aves, insectos y mamíferos. La ganadería extensiva también contribuyó a que muchos campesinos migraran del campo a la ciudad en busca de fuentes de trabajo. La proliferación de ciudades satélite alrededor del área metropolitana es creciente y muchas familias viven en la pobreza extrema, con serios problemas de delincuencia, epidemiológicos y psíquicos. 
Otro problema serio es la contaminación de las aguas superficiales y subterráneas en las principales cuencas hidrográficas del Valle Central. Miles de toneladas métricas de materia fecal, además de los residuos del café y desechos industriales son lanzados sin tratamiento alguno a estos ríos. Recientemente han proliferado enfermedades infecto-contagiosas que podrían estar relacionadas a la contaminación de las aguas. Tampoco existe ningún control sobre compuestos químicos como metales pesados, detergentes, agroquímicos y otros compuestos altamente tóxicos. Se ha determinado que los desechos fecales y químicos que son transportados por la red hídrica del Grande de Tárcoles, se depositan por corrientes marinas en el Golfo de Nicoya (García et al. 1999).

La situación es tanto más seria cuanto que en algunos sitios como en el Estero de Puntarenas existe ausencia de enterovirus en bivalvos producto de altas concentraciones de nitratos y sulfatos (Herrero et al. 1999). El alto grado de contaminación también ha provocado una posible disminución en la pesca y un conflicto económico serio para la mayor parte de los pescadores de la zona de Puntarenas y zonas aledañas (Escobar et al. 2006). Amén de los problemas que se presentan con la pesca del atún, el camarón y el aleteo del tiburón.

La contaminación del aire en el Área Metropolitana también es alarmante. La acumulación de gases tóxicos supera hasta diez veces las normas internacionales en lugares donde existe una mayor aglomeración de automóviles. Gran parte de los cambios climáticos a nivel nacional e internacional que sufre el planeta está relacionado con el efecto de invernadero, producto de la combustión de vehículos automotores.

Diariamente se producen miles de toneladas métricas de basura en el Valle Central. El problema es tan grave, que los representantes del Poder Ejecutivo y las Municipalidades no han dado una respuesta científico-técnica al manejo de los desechos sólidos. No se han establecido los procedimientos de evaluación de impacto ambiental de forma adecuada. Las comunidades no están dispuestas a aceptar los rellenos sanitarios, debido a los malos procedimientos empleados por las autoridades y a intereses particulares que se manejan atrás de esta situación. En muchos casos, los desechos sólidos se lanzan a ríos, lotes y vías de comunicación, produciendo un serio impacto estético, paisajístico y de salud.

El uso sin control de agroquímicos contribuye a la contaminación de otras zonas de pesca en el país. Es así como gran cantidad de arrecifes de coral en la costa Caribe han desaparecido por contaminación de plaguicidas y pesticidas utilizados en las plantaciones bananeras, acabando con $75 \%$ de los arrecifes coralinos localizados al sur del río la Estrella (Cortés 1995). Al eliminarse el arrecife, la ictiofauna ha disminuido considerablemente y muchos pescadores de Cahuita, Puerto Viejo y Manzanillo se han perjudicado por la destrucción de estos ecosistemas marinos. Además, la construcción del muelle de Limón alteró el régimen de corrientes marinas, provocando la erosión del litoral y la sedimentación de partículas en las colonias coralinas. Otro factor que ha alterado la zona del Caribe, es el crecimiento y construcción desordenada de hoteles y vivienda desde Puerto Viejo hasta Manzanillo. Se han violado leyes que regulan la construcción en refugios de vida silvestre, reservas indígenas y la zona marítimo terrestre, todo por falta de ética administrativa y controles ambientales a quienes la ley obliga.

En la costa Pacífica la situación no deja de ser menos grave. Se construyen hoteles en todo el litoral sin la adecuada protección ambiental; los concesionarios adeudan millones de colones al Estado por derecho de ocupación. Tampoco se exige una evaluación de impacto ambiental antes de otorgar los permisos de construcción. Las playas nacionales se convirtieron en lugares de difícil acceso para los costarricenses y se alteran importantes ecosistemas del bosque seco tropical. El río Tempisque, principal fuente de agua en la provincia de Guanacaste, sufre también el impacto de la contaminación producida por plaguicidas provenientes de zonas algodoneras, arroceras, cañeras y ganaderas. 


\section{Nacimiento del movimiento ecologista en Costa Rica}

Producto de esta crisis social, política y ambiental que ha experimentado el mundo y en especial nuestro país, nace el Comité de Defensa del Patrimonio Nacional (CDPN), el 24 de abril de 1970, como la primera organización ecologista costarricense. Organización fundada por Ricardo Quesada López-Calleja, connotado abogado y escritor nacional. Quesada fue presidente del CDPN durante 23 años y lideró importantes luchas en defensa del patrimonio cultural y natural costarricense.

A raíz de la discusión del contrato ley que se aprobó en la Asamblea Legislativa para explotar cientos de hectáreas de suelo y subsuelo nacional para extraer bauxita por la compañía Aluminium Company of America (ALCOA), nació el movimiento ecologista nacional. Es así como se inicia una de las etapas más importantes en la historia de las luchas costarricenses para proteger el ambiente.

Durante la década de los sesenta y setenta se crean los parques nacionales y áreas protegidas en todo el territorio nacional. El CDPN contribuyó de manera significativa con varias administraciones para el establecimiento de parques como Santa Rosa, Cahuita, Poás, Manuel Antonio, así como el Monumento Nacional Guayabo. Posteriormente se establecieron otras áreas protegidas que hoy forman parte del Sistema Nacional de Áreas de Conservación. En la actualidad, las áreas de conservación se encuentran en una grave crisis administrativa y financiera, a pesar de que los parques nacionales generan más divisas que el banano, café y piña juntos (Periódico La Nación 2005).

En el año 1974, el CDPN inició una fuerte campaña contra intereses internacionales y nacionales que pretendían convertir la Isla del Caño en un casino, sin importar su riqueza arqueológica y biológica. Gracias a la lucha que lideró el CDPN, la isla se declaró reserva biológica y hoy forma parte del Área de Conservación Osa. Lo mismo sucedió con la Isla del Coco, intereses ajenos a Costa Rica pretendieron hacer de la isla un garito internacional. En 1976, el Gobierno de Costa Rica y el CDPN invitaron a la Sociedad Cousteau a realizar un viaje científico y de reconocimiento a la isla para reafirmar nuestra soberanía. Posteriormente la isla se declara parque nacional y reserva biológica en junio de 1976 y Patrimonio Natural de la Humanidad por la UNESCO en diciembre de 1997. Debido la posición geográfica de la Isla del Coco, Costa Rica tiene un territorio continental y marino más grande que todo el territorio centroamericano.

La defensa de nuestra riqueza arqueológica fue otra importante lucha que inició el CDPN en esa misma década. Durante muchos años se explotó y saqueó el patrimonio cultural de los costarricenses. Gestiones a nivel nacional e internacional fueron realizadas por el CDPN para proteger el pasado aborigen costarricense. Se recuperó gran cantidad de material arqueológico tanto en Costa Rica, como en los Estados Unidos. En el estado de California, después de un largo y complejo juicio, se recuperaron cientos de piezas con un valor que superaba el millón de dólares. El juicio fue de gran trascendencia para el país y el resto de la comunidad latinoamericana de naciones, ya que se estableció jurisprudencia, y así, poder recuperar el patrimonio arqueológico sustraído del territorio nacional (Quesada 1980).

Actividades en defensa de la vida silvestre también fueron realizadas por el CDPN. La muerte de 325 cetáceos, delfines, en Bahía Ballena, Playa de Tambor fue denunciada por esta organización. Cinco mil toneladas de amoniaco anhidro, destinadas a una compañía de fertilizantes, fue lanzada a la entrada de Bahía Ballena cuando pasaba una población de delfines cerca del barco. Se denunció públicamente el hecho a través de un video realizado por la Televisora Tica y el CDPN. Fue el primer video ambiental que se hizo en el país en 1976.

En el año 1979 se promovió una campaña en la Asamblea Legislativa para proteger la tortuga verde del Caribe. Intereses espurios pretendían modificar las leyes que protegían a estos quelonios. Lo mismo se hizo en 1986 contra el Convenio del Atún que entregó a 
compañías internacionales nuestra riqueza atunera del Pacífico. La pesca masiva del atún trajo como consecuencia la muerte de cientos de delfines que quedaban atrapados en las redes de pesca. La situación fue tan grave que grupos ecologistas internacionales y el CDPN denunciaron el ecocidio.

Durante el año 1979, el CDPN, plantea la urgente necesidad de crear la Refugio de Vida Silvestre Gandoca-Manzanillo para proteger los bosques del Caribe Sur contra la expansión bananera y el acelerado crecimiento turístico que desde esa época se perfilaba para la zona. Años más tarde la situación se complicó en extremo, toda vez que funcionarios inescrupulosos de la administración pública otorgaron una gran cantidad de concesiones dentro del refugio violentando la zona marítimo terrestre y la regulaciones ambientales establecidas para el refugio. Recientemente, la Sala Primera de la Corte Suprema de Justicia ordenó al Ministerio del Ambiente y Energía demoler un hotel que había contado con todo el respaldo y los permisos de la administración 90-94.

En agosto de 1977 se instala la primera Comisión Investigadora que determina la Contaminación de las Aguas del Golfo de Nicoya y Mar Patrimonial. Una vez más la comisión fue propuesta por el CDPN a un grupo de diputados de la Asamblea Legislativa de la época. El propósito de la comisión fue evaluar el impacto ambiental que sufre el Valle Central por contaminación agroindustrial y fecal de sus principales cuencas hidrográficas, tanto a nivel superficial como subterráneo. Además, de la evaluación del impacto negativo que se produce en el ambiente por la contaminación del agua, se propuso la creación de un Centro de Investigación en Contaminación Ambiental, con sede en la Universidad de Costa Rica (UCR). Sin embargo, la contaminación de las aguas en el Valle Central es alarmante y el problema no ha sido resuelto, ni por autoridades públicas ni privadas.

El establecimiento del Parque Nacional Braulio Carrillo fue otra importante lucha realizada por organizaciones estudiantiles y el CDPN. Se propone, ante la Asamblea
Legislativa, crear el parque como la única posibilidad para proteger ecosistemas sumamente frágiles. La preocupación que expresó el CDPN, sobre los impactos ambientales que se producirían en esa carretera, ha quedado demostrada durante todos estos años por la muerte de cientos de costarricenses producto de deslizamientos que se producen todos los años a lo largo de ese trayecto.

En cinco oportunidades diferentes el CDPN logró movilizar estudiantes, campesinos, obreros e intelectuales para que no se introdujera al país un oleoducto interoceánico por parte de las compañías petroleras más poderosas del planeta. Argumentos científico-jurídicos en materia de Evaluación de Impacto Ambiental (EIA), preparados por un grupo de especialistas nacionales, permitió que un número importante de diputados derogara en 1980 la ley 5500, que permitía la introducción de oleoductos en Costa Rica.

En esa misma década también se introduce en el Código de Minería o ley 6797, la EIA como requisito obligatorio antes de otorgar concesiones mineras. Se crea la Comisión Gubernamental de Control sobre los Estudios de Impacto Ambiental. La Comisión tenía como propósito revisar los informes de impacto ambiental que presentaban los concesionarios. Posteriormente, la Comisión se transforma en la Secretaría Técnica Ambiental (SETENA).

En 1986 se establece el Ministerio de Recursos Naturales, Energía y Minas (MIRENEM), como la primera institución pública encargada de fijar políticas ambientales a nivel nacional. Un grupo de jóvenes profesionales, especialistas en materia ambiental, dirigió por primera vez en la historia nacional un ministerio de este calibre. Los resultados fueron altamente satisfactorios porque se establecieron programas de planificación ambiental en los sectores de áreas protegidas, energía, bosques, minas, vida silvestre y turismo. Se crearon nuevos parques nacionales como el Parque Nacional Juan Castro Blanco en 1993 y el Parque Marino Las Baulas en 1995 El primero se creó para proteger las nacientes de agua del cantón de San Carlos, toda vez que un 
grupo de extranjeros, de dudosa procedencia, pretendía explotar el azufre de la zona, produciendo severos impactos ambientales, y el segundo para proteger la zona de anidamiento más importante del Pacífico de la tortuga baula. Intereses privados pretendían establecer urbanizaciones en la zona de anidamiento de esas tortugas.

Se firmaron convenios internacionales en materia ambiental con Canadá, Estados Unidos, Europa y algunos países africanos y asiáticos. Se firmó, en 1988, un acuerdo con el gobierno de Canadá para realizar un informe de impacto ambiental sobre la mina Macacona, en la zona de Esparza. Esta fue la primera vez en la historia ambiental de nuestro país que un grupo de especialistas internacionales realiza un informe de este calibre. El documento sirvió para cerrar la mina y establecer el primer programa de recuperación ambiental de la mina a cielo abierto más grande en América Central en 1989.

Se iniciaron programas de educación ambiental, formal y no formal, en asociaciones de desarrollo, rurales, urbanas y en centros de enseñanza primaria y secundaria. Se impartieron conferencias en universidades públicas y privadas y se firmaron convenios de cooperación entre el ministerio y esos centros de educación superior.

Se establece la primera jurisprudencia ambiental en la Sala Constitucional contra la explotación a cielo abierto de tajos que ponía en riesgo el abastecimiento de agua del Gran Área Metropolitana (Quesada 1990). Es la primera vez que el Poder Ejecutivo del Gobierno de Costa Rica, en 1986, contó con un grupo de profesionales del más alto nivel académico, ético e intelectual y de gran trayectoria en materia ambiental.

Meses después de la creación del MIRENEM en 1986, se discute en la Asamblea Legislativa la aprobación de un préstamo multimillonario para construir una planta geotérmica en la zona de Miravalles, provincia de Guanacaste. Como el proyecto carecía de una EIA, algunos diputados del período 1986-1990 y miembros del CDPN plantearon la urgente necesidad de evaluar las consecuencias biofísicas y humanas que el proyecto podría tener en la zona. Después de largas discusiones, tanto en la Comisión Especial para Revisar el Proyecto Geotérmico de Miravalles, como en el plenario del Congreso, se exige al Instituto Costarricense de Electricidad (ICE), presentar un informe de impacto ambiental y justificar ambientalmente el proyecto.

Paralelo a la discusión del proyecto geotérmico de Miravalles, el CDPN plantea la urgente necesidad de introducir en la Constitución Política un título único de Derechos y Garantías Ambientales, la redacción de un Código del Ambiente, la creación de una Comisión Especial de Ambiente en la Asamblea Legislativa, la transformación del MIRENEM a Ministerio del Ambiente y, así como la Procuraduría Ambiental. Con estas transformaciones ecológico, jurídicas y administrativas, tanto el Estado, como los particulares, contarían con mecanismos y procedimientos efectivos para proteger el patrimonio ambiental de la nación y asegurarle a las presentes y futuras generaciones un ambiente ecológicamente sostenible.

\section{Garantías Ambientales un nuevo modelo ecológico-político para Costa Rica y el Mundo}

En la actualidad muchos de estos proyectos ya son leyes de la República, gracias a la lucha que un grupo de costarricenses y el CDPN realizó en pro del ambiente. Además, se incorporó en la carta fundamental un párrafo sobre el derecho a un ambiente sano, la responsabilidad del Estado a garantizar, defender y preservar ese derecho, así como la acción popular (Artículo 50 de la Constitución Política de Costa Rica).

El artículo 50 de la Constitución Política establece que "Toda persona tiene el derecho a un ambiente sano y ecológicamente equilibrado. Por ello, está legitimada para denunciar los actos que infrinjan ese derecho y para reclamar el daño causado. El Estado garantizará, defenderá y preservará ese derecho. La ley determinará las responsabilidades y las sanciones 
correspondiente (Ley № 7412 de 3 de junio de 1994, publicado en la Gaceta $\mathrm{N}^{\mathrm{o}} 111$ de 10 de junio de 1994).

La enmienda al artículo 50 de la Constitución, la ratificación de diversos convenios y tratados internacionales en materia ambiental, el establecimiento de la Ley Orgánica del Ambiente, la Ley de Vida Silvestre, la Ley de Biodiversidad, el establecimiento de la Comisión Especial de Ambiente en la Asamblea Legislativa, la creación del Ministerio del Ambiente y la Procuraduría Ambiental son parte de la gran transformación jurídico-administrativa que experimentó el país a finales del siglo veinte.

No obstante, estos derechos, deberes y obligaciones que tiene el Estado y la sociedad cambian muy lentamente y los problemas ambientales (agua, aire, energía, fenómenos naturales destructivos, vida silvestre, marina y terrestre, minas y crecimiento urbano) aumentan, en la mayoría de los casos, exponencialmente. Si bien es cierto que organizaciones ambientalistas, conservacionistas, ecologistas, grupos comunales, colegios profesionales, entidades públicas y privadas han utilizado estos derechos ecológico-jurídicos para proteger los ecosistemas costarricenses en contra de la explotación de aguas continentales y marinas, energía, vida silvestre, hidrocarburos y minas, también es cierto que no se le ha dado una solución contundente a tan grave situación.

Por tanto, es fundamental incluir en la Constitución Política un título de Derechos y Garantías Ambientales donde el Estado garantice, defienda y preserve el derecho a un ambiente biofísico y humano ecológicamente sostenible, donde se mantenga el dominio público sobre los elementos del ambiente, donde se regule su uso y aprovechamiento de conformidad con las reglas de la ciencia y la técnica, para que las personas tengan el derecho a un ambiente ecológicamente sostenible, para establecer un control y uso adecuado de organismos genéticamente modificados o transgénicos, para proteger el ambiente por medio de la educación, para establecer reglas claras frente a los tratados de libre comercio, para crear una institución científica pública que responda a los intereses ambientales de la sociedad y finalmente para que todos los costarricenses denuncien los actos que atenten contra el ambiente a través de la acción popular, incluyendo el principio de duda a favor del ambiente. Para que los derechos ecológicos sean debidamente tutelados por el Recurso de Amparo y la Acción de Inconstitucionalidad, como derechos fundamentales que son. Para que Costa Rica sea el primer país en el mundo con un Título de Derechos y Garantías Ambientales, para que dé el ejemplo al concierto de naciones en materia ambiental y se convierta en el primer Estado Ambiental de Derecho. Para que el ciudadano y la sociedad cuenten con un instrumento ágil y eficiente para proteger el ambiente y establecer los Derechos de Cuarta Generación en Costa Rica y en el resto de las naciones.

Para asegurarle a los seres humanos y a las demás especies, la vida y existencia en el planeta Tierra y transformar los paradigmas clásicos y neoclásicos en un nuevo modelo ecológico-político para Costa Rica.

El texto para introducir un Título de Garantías Ambientales en la Constitución Política de Costa Rica fue suscrito por el Presidente de la República, Abel Pacheco y el Movimiento Ecologista Costarricense el 14 de setiembre de 2002 en la casa de Víctor Quesada y Hortensia López-Calleja, lugar donde sesenta años atrás, se gestaron las Garantías Sociales (Vega 1988). Posteriormente, el proyecto de ley fue aprobado en la Asamblea Legislativa con dictamen afirmativo de mayoría por la Comisión Especial para adicionar un Título de Garantías Ambientales. 


\section{La Asamblea Legislativa de la República de Costa Rica}

Decreta:

\section{Introducir un Título de Derechos y Garantías Ambientales en la Constitución Política}

Artículo 1.- Créase un nuevo título VI en la Constitución

Política, corriendo la numeración, que se leerá así:

\section{TITULO VI \\ Derechos y Garantías Ambientales}

\section{Capítulo Único}

Artículo 75.- El Estado garantiza, defiende y preserva el derecho a un ambiente físico, biológico y humano ecológicamente sostenible para asegurarle una mejor calidad de vida a todos los habitantes de la nación.

Artículo 76.- El Estado garantiza, defiende, preserva, y mantiene el dominio absoluto, inalienable e imprescriptible sobre el aire, el agua, el subsuelo, el suelo, la diversidad biológica y sus componentes, así como los minerales, los hidrocarburos, los recursos energéticos, costeros, marinos, el mar patrimonial, la zona marítima de exclusión económica y las áreas protegidas de la nación. Mediante la ley, el Estado regulará su uso y aprovechamiento público y privado, para que el mismo sea de conformidad con las reglas de la ciencia, la técnica y el interés público. El Estado fomentará el uso de formas de energía y tecnologías limpias y sostenibles. Solo se permitirá el uso del ambiente y de las fuentes energéticas de conformidad con los principios aquí establecidos.

Artículo 77.- Toda persona tiene derecho a un ambiente, físico, biológico, cultural, económico, social y humano ecológicamente sostenible. El respeto al ambiente y el uso adecuado de los recursos naturales son deberes de todos los habitantes.

Artículo 78.- Toda actividad pública o privada que afecte el componente bioquímico y genético del país, estará obligada a cumplir las reglas y principios de una efectiva gestión ambiental con el fin de garantizar un desarrollo ecológicamente sostenible.

Artículo 79.- El Estado fomentará una ética colectiva en materia ambiental a través de la educación.

Artículo 80.- Una institución científica pública aportará al Estado los criterios que se requieran para el establecimiento de las políticas ambientales y un desarrollo ecológico, económico y socialmente sostenible.

Artículo 81.- Toda persona está legitimada para denunciar los actos que pongan en peligro los derechos y garantías establecidas en este Título y reclamar la reparación del daño causado. Las acciones para evitar y corregir situaciones de deterioro ambiental son públicas. $\mathrm{La}$ Ley determinará las responsabilidades y las sanciones de las personas naturales y jurídicas en materia ambiental incluyendo el criterio de duda a favor del ambiente.

Artículo 2.- Para efectos de la adición a la Constitución Política del nuevo Título VI Garantías Ambientales, se corre en uno la numeración de los siguientes Títulos, a partir del actual Título VI La Religión y se corre en siete los artículos, a partir del actual artículo 75 .

Artículo 3.- Se deroga el párrafo segundo y el párrafo tercero del artículo 50 de la Constitución Política

Rige a partir de su publicación

Expediente No. 14.919, publicado en La Gaceta No. 226 del 24 de noviembre de 2006 


\section{RESUMEN}

La Constitución Política de Costa Rica incluye un párrafo sobre el derecho a un ambiente sano, la responsabilidad del Estado a garantizar, defender y preservar ese derecho, así como la acción popular (Artículo 50). Sin embargo, es fundamental incluir en la Constitución un título de Derechos y Garantías Ambientales donde el Estado garantice, defienda y preserve el derecho a un ambiente biofísico y humano ecológicamente sostenible, donde se mantenga el dominio público sobre los elementos del ambiente, y se regule su uso y aprovechamiento de conformidad con las reglas de la ciencia y la técnica. Costa Rica sería el primer país en el mundo con un título constitucional de Derechos y Garantías Ambientales y daría el ejemplo a otras naciones en materia ambiental. Las Garantías Ambientales serán un instrumento ágil y eficiente para proteger el ambiente.

Palabras clave: ambiente, sostenibilidad ambiental, dominio público, garantías ambientales.

\section{REFERENCIAS}

Brown, L. 2001. Eco-Economy. Building an economy for the Earth. W.W. Norton \& Company, Nueva York, EEUU.

Cortés, J. 1995. El arrecife coralino del Parque Nacional Cahuita: un arrecife con problemas ambientales. Biocenosis $11: 23-24$.

Escobar, J. 2006. Inventario y revisión de fuentes de contaminación y actividades en tierra que afectan el medio marino y áreas costeras del Pacífico Nordeste. Inventario Regional. Comisión Centroamericana de Transporte Marítimo, Programa de Naciones Unidas para el Medio Ambiente y Agencia Sueca para el Desarrollo.

García, V., J. Acuña-González, J. Vargas-Zamora, \& J. García Céspedes. 2006. Calidad bacterológica y desechos sólidos en cinco ambientes costeros de Costa Rica. Rev. Biol. Trop. 54: 34-48.

Herrero, L., A. Palacios, L. Hun \& F. Vega. 1999. Ausencia de detección de enterovirus en bivalvos Anadara tuberculosa (Bivalvia: Arcidae) por contaminación química en el Pacífico de Costa Rica. Rev. Biol. Trop. 47: 419-427.
Lotka, A. J. 1922. Contribution to the energetics of evolution. Proc. Natl. Acad. Sci. 8:151-154.

Margulis, L. 1998. Symbiotic Planet. A new look at life on Earth. Brockman. Massachussets, EEUU.

Mata, A. \& F. Quevedo. 2005. Diccionario didáctico de ecología. Universidad de Costa Rica, San José, Costa Rica.

Obando, V. 2002. Biodiversidad en Costa Rica. Sistema Nacional de Áreas de Conservación. Instituto Nacional de Biodiversidad, Heredia, Costa Rica.

Odum, H. 1983. Systems Ecology: an introduction. Wiley, Nueva York, EEUU.

Periódico La Nación. 2005. Parques generaron más ingresos al año que banano, café y piña. San José, Costa Rica.

Quesada, G. 1990. Primera Jurisprudencia Ambiental. El Panchito Sociedad Anónima contra Comisión Gubernamental de Control sobre los Estudios de Impacto Ambiental, Voto 329-90. Sala Constitucional, San José, Costa Rica.

Quesada, G. 1992. Vital para Costa Rica veredicto en Tribunal Internacional del Agua. Periódico La Nueva Fuerza. San José, Costa Rica.

Quesada, G. 2008. Ecología Económica. Programa garantías ambientales. Universidad Estatal a Distancia, San José, Costa Rica.

Quesada, R. 1980. Costa Rica. La frontera Sur de Mesoamérica. Incafo, España.

Reppeto, R. 1992. Accounting for environmental assets. Scientific American 8: 94-100.

Smith, R.L. \& T.M. Smith. 2001. Ecología. Pearson, España.

Vega, J. 1988. Avatares en la vida de Carmen Lyra. Revista Nacional de Cultura 1: 5-6.

von Bertalanffy, L. 1987. Historia y situación de la Teoría General de los Sistemas, p. 27-53. En: von Bertalanffy, L, Ashby, W. R, Weinberg, G. M y otros. Tendencias en la teoría general de sistemas. Alianza, España. 